Research Article

\title{
Aetiopathogenesis of Laryngotracheal Stenosis: A Retrospective Review
}

\section{Bigyan Raj Gyawali $\left(\mathbb{D}\right.$, Rabindra Bhakta Pradhananga, Kunjan Acharya ${ }^{(D)}$ Heempali Dutta, Yogesh Neupane, Dharma Kanta Baskota, and Rajendra Guragain}

Department of ENT-HNS, Maharajgunj Medical Campus, Institute of Medicine, T.U. Teaching Hospital, Kathmandu, Nepal

Correspondence should be addressed to Bigyan Raj Gyawali; bigyan.gyawali@gmail.com

Received 25 August 2019; Revised 1 August 2020; Accepted 29 August 2020; Published 22 September 2020

Academic Editor: Gerd J. Ridder

Copyright (C) 2020 Bigyan Raj Gyawali et al. This is an open access article distributed under the Creative Commons Attribution License, which permits unrestricted use, distribution, and reproduction in any medium, provided the original work is properly cited.

Background. Airway stenosis is a technically challenging pathology to deal with. Various aetiologies can lead to the stenosis; however, trauma, mostly related to intubation, is the commonest so far. This study retrospectively evaluates various aetiological factors resulting in airway stenosis and the associated patient-related factors. Objectives. The objectives of this study were to evaluate the common patient-related factors, aetiology, site, and mode of presentation of airway stenosis and to evaluate the duration of intubation resulting in airway stenosis. Materials and methods. This was a retrospective study carried out at the Department of ENT-HNS, Institute of Medicine, Nepal. Record files from January 2014 to January 2019 of all cases with endoscopic diagnosis of airway stenosis were evaluated. Demographic data, site, severity, aetiology, time, and mode of presentation were noted. The severity of stenosis was graded based on Cotton-Meyer (CM) classification. Results. A total of 33 cases were included in the study. The trachea and the subglottis were the frequent sites to be involved. Intubation-related trauma was the commonest aetiology with a shortest duration of intubation of only 4 days resulting in development of the stenosis. The other aetiologies were congenital, trauma, inflammation, and idiopathic. Conclusion. Trauma, mostly related to intubation, is still the commonest cause for the development of airway stenosis. Along with the duration of intubation, there are several other factors that can affect the development of stenosis. A prospective study with a large population is required to draw a definite conclusion.

\section{Introduction}

Airway stenosis is one of the challenging pathologies to treat in the field of otorhinolaryngology. It can be at the level of supraglottis, glottis, subglottis, or trachea. Of the wide range of aetiologies described, e.g., congenital, traumatic, inflammatory, and idiopathic $[1,2]$, trauma following prolonged intubation and tracheostomy is still considered the commonest aetiology for the development of airway stenosis in both paediatric [3] and adult population [2, 4]. Aetiological factors, however, may vary in their prevalence in different geographical regions. As stated by Gelbard et al., airway stenosis is an anatomical definition with a diverse pathogenesis. Moreover, various patient factors are known to affect the development of the stenosis, e.g., gender, obesity, and type II DM $[2,5]$. Considering the fact, the management strategy for this entity should be tailored on an individual basis.

The study retrospectively evaluates a unique cohort of Nepalese population with documented laryngotracheal stenosis for the common patient-related factors such as age, sex and comorbid conditions, aetiology, site and mode of presentation, and the duration of intubation resulting in airway stenosis.

\section{Materials and Methods}

This was a retrospective study carried out at the Department of ENT-HNS, Institute of Medicine, Nepal. Approval for the study was taken from the Institutional Review Committee. All cases with the endoscopic diagnosis of airway stenosis were included in the study, and the records lacking the 
evidence of endoscopic evaluation of airway were excluded. The record files of the past five years (January 2014-January 2019) were evaluated by the investigator. Age, sex, site of the stenosis, severity of the stenosis, aetiology, time and mode of presentation, and comorbidities associated with the patient were noted. Cases below 15 years of age were kept under the paediatric group, and cases with age 15 years or above were kept in the adult group. The severity of the stenosis was graded based on the Cotton-Meyer (CM) classification [6]. Stenosis involving up to $50 \%$ of the circumference of the airway was considered grade I, $51-70 \%$ of the circumference was considered grade II, 71-99\% of the circumference was considered grade III, and cases with undetectable lumen were considered grade IV. The severity of the stenosis was defined subjectively based on the endoscopic picture. Comorbidities were evaluated based on patient's medical records. Any chronic medical or surgical conditions affecting the well-being of the patient were considered for the evaluation, e.g., obesity (BMI $\left.>30 \mathrm{~kg} / \mathrm{m}^{2}\right)$, diabetes mellitus (DM), hypertension (HTN), immune-compromised status, malignancies, and chronic lung disease. Our total sample size was 33. The data analysis was performed using SPSS version 21. The chi-square test was used for the evaluation of the statistical association. $P$ value $<0.05$ was considered statistically significant.

\section{Results}

A total of 33 cases were included in the study. Majority of the cases were adults. There was an almost equal prevalence of the both genders. Six adult cases had gastroesophageal reflux disease (GERD), which was diagnosed based on the history and features of laryngopharyngeal reflux, i.e., congested arytenoids, in endoscopy. Two of them had subglottic and four had tracheal stenosis. All cases were related to postintubation trauma. Two adult cases had type II DM. These cases developed subglottic stenosis following intubation trauma. One child with glottic stenosis had IgA deficiency with interstitial lung disease (Table 1).

Of the 33 cases with airway stenosis, trachea was found to be affected in 18 cases, which was the commonest site. Subglottis was affected in 10 cases followed by isolated involvement of glottis in 4 and supraglottis with glottis in 1 case.

There were total of 4 cases with isolated glottic stenosis (Figures 1 and 2) and only one case with supraglottic with glottic stenosis (Figure 3). All of these cases belonged to the paediatric age group. The aetiologies are mentioned in $\mathrm{Ta}-$ ble 2. Majority of the cases with stenosis in the subglottis (Figures 4-6) and trachea (Figure 7) were in adults, and the commonest cause was prolonged intubation in both paediatric and adult population. Five out of 6 adult cases with subglottic stenosis and 16 out of 18 adult cases with tracheal stenosis had a history of prolonged intubation. Similarly, of 4 paediatric cases with subglottic stenosis, 3 had a history of prolonged intubation. One paediatric case had congenital subglottic stenosis, which was diagnosed immediately following birth due to stridor. One adult case had idiopathic subglottic stenosis, which was diagnosed after excluding all the possible causes. There was one case each of blunt trauma larynx and relapsing perichondritis causing tracheal stenosis (Table 3).

Of the 33 cases with airway stenosis, $72.7 \%$ (24) cases had a history of intubation. Most of the cases were diagnosed following repeated failure of extubation or failed decannulation of the tracheostomy tube. The duration of intubation, site, and grading of stenosis are given in Table 4. Correlation between duration of intubation and severity of stenosis did not show any statistical significance (Table 5).

\section{Discussion}

The management of airway stenosis is very challenging. While a wide range of aetiologies exist, traumatic cause, mostly resulting from intubation of the airway, still is the commonest cause prevalent worldwide and a preventable one. Considering the global burden of this pathology, this study provides data on the aetiopathogenesis of laryngotracheal stenosis in a unique cohort of the Nepalese population.

In this study, $9(27 \%)$ cases were of the paediatric age group. Among the rest, most of the patients (40\%) were of the 15-30 years age group. An equal prevalence of airway stenosis between male and female was seen. In paediatric population, variation in the site of airway stenosis ranging from supraglottis to glottis was seen. Tracheal involvement, however, was not seen in this age group. Supraglottic with glottic stenosis, a very complicated airway pathology, was seen in one case. It resulted due to accidental strangulation. Airway injury due to accidental strangulation mostly results from entrapment of shawls and muffler at the place of work with running machineries. In a study by Pookamala et al. [7] in India, of 60 cases with laryngotracheal stenosis, 15 (25\%) cases had a history of accidental strangulation. However, the subglottis and trachea were the common sites to be involved followed by glottis.

Glottic stenosis was predominantly seen in paediatric population in our study. One case had congenital stenosis and was detected by flexible laryngoscopic examination following persistent stridor immediately after birth. Two cases developed stenosis following acute laryngitis and surgical excision of respiratory papillomatosis and presented with progressive change in voice and shortness of breath. In both cases, there was anterior glottic stenosis (Figure 2). One case had interstitial lung disease with IgA deficiency, and glottis stenosis was detected after having repeated failures of extubation (Figure 1). This case had a circumferential stenosis. Glottic stenosis is clinically identified as a narrow glottic aperture resulting from anterior, posterior, or circumferential membranous web. Congenital glottic stenosis is very rare and results usually from inadequate recanalization of larynx during embryonic development [8]. Acquired stenosis, on the other hand, is relatively common resulting from internal laryngeal trauma such as intubation, caustic ingestion, external laryngeal trauma, and granulomatous inflammations. Intubation-related trauma is the commonest one [9], and the incidence of glottic stenosis related to intubation trauma varies from $4 \%$ to $14 \%$ [10]. 
TABLE 1: Age group and gender distribution among the cases with identified comorbid conditions.

\begin{tabular}{ccc}
\hline Age group & Male & Female \\
\hline Paediatric $(<15$ years $)$ & 4 & 5 \\
Adult $(\geq 15$ years $)$ & 12 & 12 \\
\hline Pre-morbid conditions & Site of stenosis & Number of cases \\
\hline GERD & Sub-glottis/trachea & 6 \\
Type II DM & Sub-glottis & 2 \\
IgA deficiency & Glottis & 1 \\
\hline
\end{tabular}

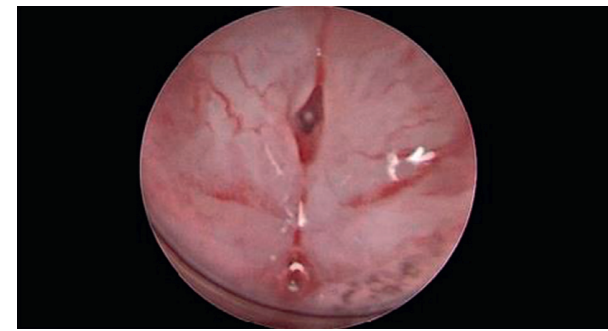

FIGURE 1: Circumferential glottic stenosis.

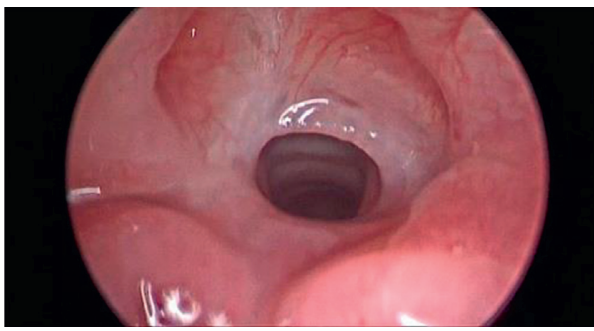

Figure 2: Anterior glottic web.

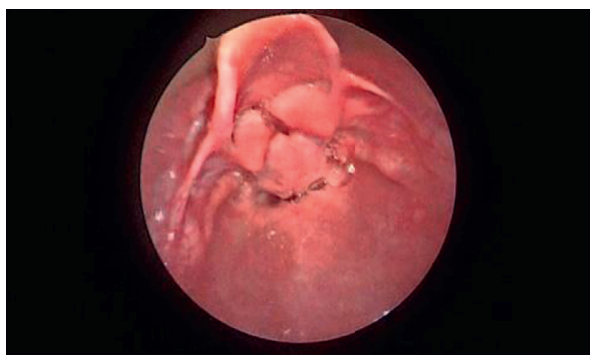

Figure 3: Supraglottic and glottic stenosis.

TABLE 2: Sites of airway stenosis.

\begin{tabular}{lc}
\hline Site of stenosis & No. of patients $(n=33)$ \\
\hline Supraglottis and glottis & 1 \\
Glottis & 4 \\
Sub-glottis & 10 \\
Trachea & 18 \\
\hline
\end{tabular}

Mucosal injuries during intubation at the level of glottis commonly occur at the medial surface of vocal process of arytenoids and interarytenoid region [11]. Howard et al. [10]

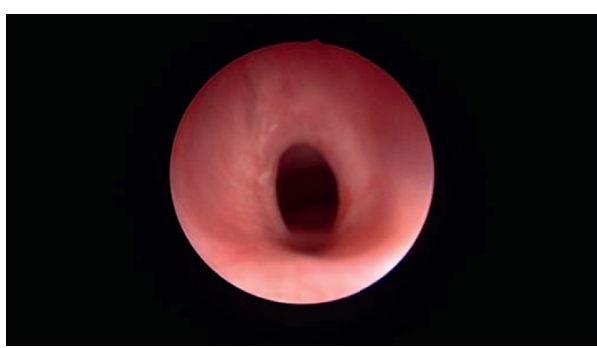

Figure 4: Grade I subglottic stenosis.

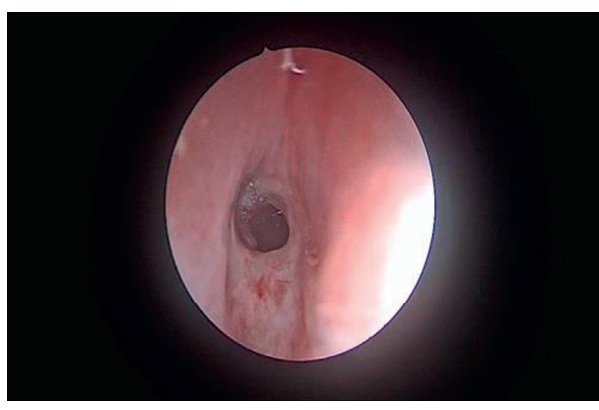

FIGURE 5: Grade II subglottic stenosis.

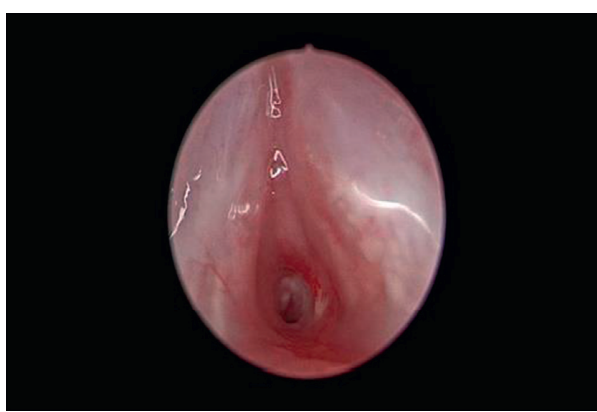

Figure 6: Grade III subglottic stenosis.

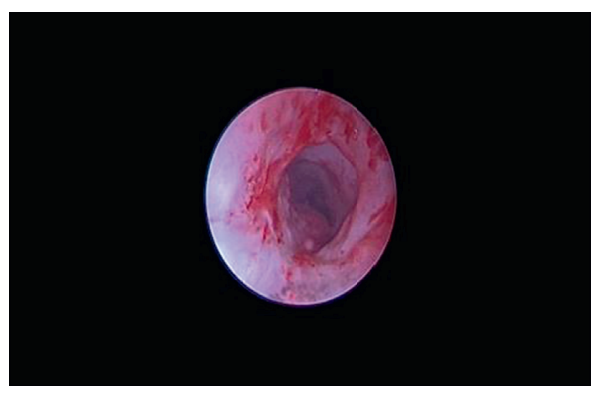

Figure 7: Grade I tracheal stenosis.

have reported two cases with a photodocumentation of progression to posterior glottis stenosis following intubation trauma. One of our cases had a history of repeated failures of extubation. The case had interstitial lung disease with selective IgA deficiency. It was unclear whether the respiratory mucosal inflammation or the intubation-related trauma caused the stenosis. Perkins et al. [12] have reported that in 
TABLE 3: Aetiology of airway stenosis according to age distribution and clinical features.

\begin{tabular}{|c|c|c|c|}
\hline Sites & $\begin{array}{l}\text { Age } \\
\text { group }\end{array}$ & $\begin{array}{l}\text { Number of } \\
\text { cases }\end{array}$ & Clinical features leading to diagnosis \\
\hline \multicolumn{4}{|l|}{ Supraglottic with glottic stenosis } \\
\hline Blunt trauma & $\mathrm{P}$ & 1 & Failed decannulation \\
\hline \multicolumn{4}{|l|}{ Glottis } \\
\hline Congenital & $\mathrm{P}$ & 1 & Stridor since birth \\
\hline Acute laryngitis & $\mathrm{P}$ & 1 & Progressive shortness of breath with change in voice \\
\hline $\begin{array}{l}\text { Interstitial lung disease with IgA } \\
\text { deficiency }\end{array}$ & $\mathrm{P}$ & 1 & Repeated failures of extubation \\
\hline Following excision of RRP & $\mathrm{P}$ & 1 & Progressive shortness of breath with change in voice \\
\hline \multicolumn{4}{|l|}{ Subglottis } \\
\hline Prolonged intubation & $\begin{array}{l}\mathrm{P} \\
\mathrm{A}\end{array}$ & $\begin{array}{l}3 \\
5\end{array}$ & Failed extubation/failed decannulation of the tracheostomy tube \\
\hline Congenital & $\mathrm{P}$ & 1 & Stridor since birth \\
\hline Idiopathic & A & 1 & Progressive respiratory distress with no obvious cause \\
\hline \multicolumn{4}{|l|}{ Trachea } \\
\hline Prolonged intubation & A & 16 & Failed extubation/failed decannulation of the tracheostomy tube \\
\hline Relapsing perichondritis & A & 1 & $\begin{array}{l}\text { Recurrent inflammation of the airway with intermittent remissions } \\
\text { with progressive stridor }\end{array}$ \\
\hline Blunt trauma & A & 1 & Failed decannulation \\
\hline
\end{tabular}

TABLE 4: Duration of intubation with site and grade of stenosis.

\begin{tabular}{|c|c|c|}
\hline Duration of intubation & Site of stenosis (no. of cases) & CM grading (no. of cases) \\
\hline$<1$ week & Trachea (4) & $\begin{array}{c}\text { Grade II (2) } \\
\text { Grade III (2) }\end{array}$ \\
\hline & Subglottis (6) & $\begin{array}{l}\text { Grade II (2) } \\
\text { Grade III (4) }\end{array}$ \\
\hline 1-2 weeks & Trachea (7) & $\begin{array}{c}\text { Grade I (1) } \\
\text { Grade II (2) } \\
\text { Grade III (4) }\end{array}$ \\
\hline$>2$ weeks & $\begin{array}{l}\text { Subglottis (2) } \\
\text { Trachea (5) }\end{array}$ & $\begin{array}{l}\text { Grade III (2) } \\
\text { Grade III (4) } \\
\text { Grade IV (1) }\end{array}$ \\
\hline
\end{tabular}

TABLE 5: Correlation between duration of intubation and severity of stenosis.

\begin{tabular}{lccc}
\hline Duration of intubation & $\begin{array}{c}\text { Severity of stenosis } \\
\text { Mild to moderate } \\
\text { (grade I and grade II) }\end{array}$ & $\begin{array}{c}\text { Moderately severe to severe } \\
\text { (grade III and grade IV) }\end{array}$ & Chi-square test \\
\hline$<2$ weeks & 7 & 7 & $P$ \\
$>2$ weeks & 0 & $P$ value $=0.315$ \\
\hline
\end{tabular}

their retrospective review of 50 cases who underwent excision of respiratory papillomatosis, seven developed iatrogenic airway stenosis. However, in contrast to our study, three of them had isolated posterior glottic stenosis, one had posterior glottic stenosis with bronchial stenosis, and the other had posterior glottic stenosis with supraglottic stenosis. Exposing the raw area on two opposing surface of vocal cords increases the risk of fibrosis and hence, stenosis.

Subglottis was the second most common site to be affected followed by the trachea in our study. Eight out of 10 cases developed stenosis after intubation, of which 3 cases were from the paediatric group and 5 cases were from the adult age group. Most of these cases were identified after failed extubation or failed decannulation. Of 6 cases who were intubated for a duration between 1 and 2 weeks, 2 cases had CM grade II stenosis and 4 cases had CM grade III stenosis. Two cases had a history of intubation $>2$ weeks, and both of them had CM grade III stenosis. Tracheal intubation is the most common factor leading to subglottic stenosis, accounting for up to $90 \%$. Gelbard et al. [2] reported 59\% of the cases with iatrogenic injury developing stenosis in the subglottic region. A retrospective study by Rodríguez et al. [13] on 71 paediatric cases with postintubation subglottic stenosis showed intubation time ranged from 4-150 days with majority of the cases (80\%) developing CM grade III stenosis followed by grade IV (18\%) and grade I (1.4\%) stenosis. Similarly, Hautefort et al. [14] in their study showed endotracheal intubation-related subglottic stenosis accounting for 
$54.5 \%$ of total cases with subglottic stenosis. Cricoid, being a complete ring of cartilage, has a higher propensity to develop stenosis following traumatic injury. Although both endotracheal intubation and tracheostomy can both cause subglottic stenosis, in our study, the majority of cases with prolonged intubation had undergone tracheostomy without endoscopic evaluation being performed for assessment of airway stenosis. In this scenario, it is difficult to tell whether the intubation or the tracheostomy caused the stenosis. Subglottic stenosis presenting congenitally is rare and usually results from failure of canalization of the primitive larynx. In our study, one of 10 cases with subglottic stenosis had congenital aetiology. A retrospective review by Choo et al. [15] showed that 2 out of 18 cases with subglottic stenosis were congenital. Congenital subglottic stenosis presents with stridor immediately after birth or may present later depending upon severity. It is not uncommon for clinicians to get this entity confused with asthma. Similarly, idiopathic subglottic stenosis is another rare entity where the cause of subglottic stenosis is not known and is usually a diagnosis of exclusion. It usually presents in young Caucasian females [16]. In our study, it was found in one case who was an adult female presenting with progressive shortness of breath. In a five-year review by Taylor et al. [17], 24 cases with idiopathic subglottic stenosis were identified where all cases were female.

Tracheal involvement was the commonest of all in our study. All 18 cases were adult, of which majority of the cases developed stenosis following prolonged intubation. Although with the advent of low pressure and high volume cuffed endotracheal tubes, the incidence of stenosis following prolonged intubation has declined, there are other factors such as intubation trauma, size of tube, patient's mobility, cardiovascular status, gender, and premorbid conditions which can influence the development of stenosis. Four cases in our study developed stenosis with intubation duration of less than 1 week. The shortest duration of intubation was 4 days. Most cases (77.7\%) had CM grade III stenosis. We could not yield a statistically significant correlation between the duration of intubation and severity of stenosis. Goranovic et al. [18] have reported a case of developing severe tracheal stenosis with a history of intubation of only two and half days. In a prospective study by Stauffer et al. [19], 19\% of cases developed tracheal stenosis following tracheal intubation. One of our cases developed tracheal stenosis due to relapsing perichondritis. Relapsing perichondritis is an autoimmune disorder with an unknown aetiology. It is characterized by recurrent inflammation of the cartilaginous and connective tissue of the body and is a rare cause of tracheal stenosis. Stenosis develops following recurrent attacks and remission. Around 50\% of cases with relapsing perichondritis may develop tracheal stenosis [20]. Early in the disease process, there is inflammatory swelling, which is followed by progressive destruction of laryngeal and tracheal cartilage causing collapse of the airway. At the later stage, stenosis of the airway develops due to fibrotic changes [21].

Patient factors such as gender, obesity, cardiovascular disease, and DM affecting the development of airway stenosis have been very well shown in the studies by Geblard et al. [2] and Nicolli et al. [5]. In our study, we could pick up some comorbidities such as IgA deficiency, type II DM, and GERD in cases with laryngotracheal stenosis. However, for their role in the development of the stenosis to be established, a control group for the comparison would be required.

4.1. Limitations. As this study was a retrospective study, in cases with airway stenosis developing after intubation, several confounding factors could not be assessed such as trauma or difficulty during intubation, level of sedation of the patient, type of the endotracheal tube, and frequency of suctioning. Moreover, many cases with prolonged intubation were tracheostomized during the treatment process who later on developed airway stenosis. Since no endoscopic evaluation of airway was performed prior to tracheostomy, it is difficult to conclude whether the intubation or the tracheostomy caused the stenosis.

\section{Conclusion}

Trauma, mainly related to intubation, is still the commonest cause of airway stenosis. There is no specific duration of intubation where a patient develops stenosis, as in this study, a case with just 4 days of intubation developed tracheal stenosis. Several factors play a role in the development of stenosis apart from duration of intubation. The other causes of airway stenosis are congenital, inflammatory, and idiopathic. A prospective, large-scale study with controlled parameters is further required to evaluate the aetiopathogenesis of laryngotracheal stenosis.

\section{Data Availability}

The data used to support the findings of this study are included within the article.

\section{Conflicts of Interest}

The authors declare that they have no conflicts of interest.

\section{References}

[1] S. Nair, A. Nilakantan, A. Sood, A. Gupta, and A. Gupta, "Challenges in the management of laryngeal stenosis," Indian Journal of Otolaryngology and Head \& Neck Surgery, vol. 68, no. 3, pp. 294-299, 2015.

[2] A. Gelbard, D. O. Francis, V. C. Sandulache, J. C. Simmons, D. T. Donovan, and J. Ongkasuwan, "Causes and consequences of adult laryngotracheal stenosis," The Laryngoscope, vol. 125, no. 5, p. 1137, 2015.

[3] N. D. Jefferson, A. P. Cohen, and M. J. Rutter, "Subglottic stenosis," Seminars in Pediatric Surgery, vol. 25, no. 3, pp. 138-143, 2016.

[4] Y. Koshkareva, J. P. Gaughan, and A. M. S. Soliman, "Risk factors for adult laryngotracheal stenosis: a review of 74 cases," Annals of Otology, Rhinology \& Laryngology, vol. 116, no. 3, pp. 206-210, 2007.

[5] E. A. Nicolli, R. M. Carey, D. Farquhar, S. Haft, K. P. Alfonso, and N. Mirza, "Risk factors for adult acquired subglottic 
stenosis," The Journal of Laryngology \& Otology, vol. 131, no. 3, pp. 264-267, 2017.

[6] P. Monnier, "Partial cricotracheal resection and extended cricotracheal resection for pediatric laryngotracheal stenosis," Thoracic Surgery Clinics, vol. 28, no. 2, pp. 177-187, 2018.

[7] S. Pookamala, R. Kumar, A. Thakar, C. Venkata Karthikeyan, A. S. Bhalla, and R. C. Deka, "Laryngotracheal stenosis: clinical profile, surgical management and outcome," Indian Journal of Otolaryngology and Head \& Neck Surgery, vol. 66, no. S1, pp. 198-202, 2014.

[8] H. I. A. Zaw-Tun, "Development of congenital laryngeal atresias and clefts," Annals of Otology, Rhinology \& Laryngology, vol. 97, no. 4, pp. 353-358, 1988.

[9] K. A. Stephenson and M. E. Wyatt, "Glottic stenosis," Seminars in Pediatric Surgery, vol. 25, no. 3, pp. 132-137, 2016.

[10] N. S. Howard, T. L. Shiba, J. E. Pesce, and D. K. Chhetri, "Photodocumentation of the development of type I posterior glottic stenosis after intubation injury," Case Reports in Surgery, vol. 2015, Article ID 504791, 3 pages, 2015.

[11] B. Benjamin and L. D. Holinger, "Laryngeal complications of endotracheal intubation," Annals of Otology, Rhinology \& Laryngology, vol. 117, no. 9, pp. 1-20, 2008.

[12] J. A. Perkins, A. F. Inglis, and M. A. Richardson, "Iatrogenic airway stenosis with recurrent respiratory papillomatosis," Archives of Otolaryngology-Head \& Neck Surgery, vol. 124, no. 3, pp. 281-287, 1998.

[13] H. Rodríguez, G. Cuestas, H. Botto, A. Cocciaglia, M. Nieto, and A. Zanetta, "Post-intubation subglottic stenosis in children. Diagnosis, treatment and prevention of moderate and severe stenosis," Acta Otorrinolaringológica Española, vol. 64, no. 5, pp. 339-344, 2013.

[14] C. Hautefort, N. Teissier, P. Viala, and T. Van Den Abbeele, "Balloon dilation laryngoplasty for subglottic stenosis in children: eight years' experience," Archives of Otolaryngology-Head \& Neck Surgery, vol. 138, no. 3, pp. 235-240, 2012.

[15] K. K. Choo, H. K. Tan, and Balakrishnan, "Subglottic stenosis in infants and children," Singapore Medical Journal, vol. 51, pp. 848-852, 2010.

[16] H. C. Grillo, E. J. Mark, D. J. Mathisen et al., "Idiopathic laryngotracheal stenosis and its management," The Annals of Thoracic Surgery, vol. 56, pp. 80-87, 1993.

[17] S. C. Taylor, D. R. Clayburgh, J. T. Rosenbaum, and J. S. Schindler, "Clinical manifestations and treatment of idiopathic and wegener granulomatosis-associated subglottic stenosis," JAMA Otolaryngology-Head \& Neck Surgery, vol. 139, no. 1, pp. 76-81, 2013.

[18] T. Goranovic, Z. Milan, I. Pirkl, and V. Nesek Adam, "Severe tracheal stenosis after short-term endotracheal intubation: a case report," Edorium Journal of Anesthesia, vol. 2, pp. 10-13, 2016.

[19] J. L. Stauffer, D. E. Olson, and T. L. Petty, "Complications and consequences of endotracheal intubation and tracheotomy. A prospective study of 150 critically ill adult patients," The American Journal of Medicine, vol. 70, no. 1, pp. 65-76, 1981.

[20] A. Sharma, K. Gnanapandithan, and K. Sharma, "Relapsing polychondritis: a review," Clinical Rheumatology, vol. 32, no. 11, pp. 1575-1583, 2013.

[21] S. Rafeq, D. Trentham, and A. Ernst, "Pulmonary manifestations of relapsing perichondritis," Clinics in Chest Medicine, vol. 31, no. 3, pp. 513-518, 2010. 